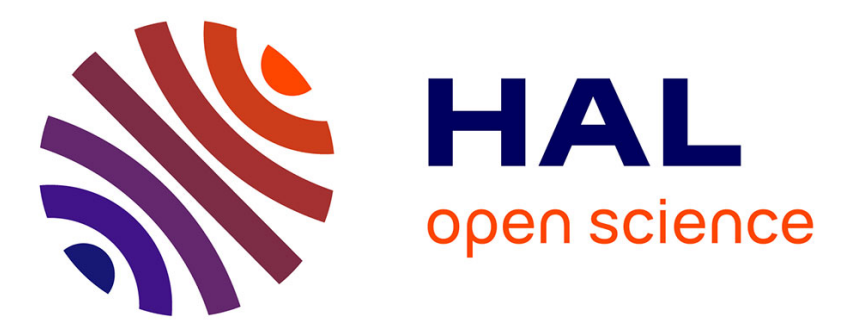

\title{
PRESSURE FLUCTUATION NUMERICAL SIMULATION IN A CENTRIFUGAL PUMP VOLUTE CASING
}

S. Timushev, B. Ovsyannikov

\section{> To cite this version:}

S. Timushev, B. Ovsyannikov. PRESSURE FLUCTUATION NUMERICAL SIMULATION IN A CENTRIFUGAL PUMP VOLUTE CASING. Journal de Physique IV Proceedings, 1992, 02 (C1), pp.C1-619-C1-622. 10.1051/jp4:19921133 . jpa-00251090

\section{HAL Id: jpa-00251090 https://hal.science/jpa-00251090}

Submitted on 1 Jan 1992

HAL is a multi-disciplinary open access archive for the deposit and dissemination of scientific research documents, whether they are published or not. The documents may come from teaching and research institutions in France or abroad, or from public or private research centers.
L'archive ouverte pluridisciplinaire HAL, est destinée au dépôt et à la diffusion de documents scientifiques de niveau recherche, publiés ou non, émanant des établissements d'enseignement et de recherche français ou étrangers, des laboratoires publics ou privés. 


\title{
PRESSURE FLUCTUATION NUMERICAL SIMULATION IN A CENTRIFUGAL PUMP VOLUTE CASING
}

\author{
S.F. TIMUSHEV and B.V. OVSYANNIKOV* \\ Engels st. 19/11, 141400 Himki, Moscow Region, USSR \\ ${ }^{*}$ Fakultetski 1. 4/20, Moscow, USSR
}

\begin{abstract}
Numericial techniques of pressure flactuation amplitude estimation at "blade frequencies" in the volute casing passage of the centrifusal pump have been developed. Fluctuating flow is represented in the form of the vortical and acoustic mode combination. The algorithm has been realized in FORTRAN programs. Estimation rezults and comparison with experimental data are out lined.
\end{abstract}

Experiments have showed that sources of hydrodynamic nature bring about considerable vibrations and noise of high speed centrifugal pumps. At the design operation mode of a centrifugal pump the main vibration source is the workins fluid pressure fluctuations at. frequencies blades follow each other ("blade frequencies"). These result from hydrodynamic interaction between unsteady flow outgoing from the impeller and a pump volute casing.

The main physical cause of pressure fluctuations generation in the centrifugal pump volute casing are vortical disturbances of the flow wich appear in passing vane channels of the impeller and are transferred at an average flow velocity. This is the oscillation vortical mode or the so called "pseudosound". Acoustic waves resulting from medium compressibility appeared in nonstationary flow being the acoustic mode.

In a suggested model subsonic isentropic flow of the warking fluid is discussed, viscous diffusion and wall friction are neglected. Then the main equations of compressed medium motion can be represented as

$$
\begin{aligned}
& \frac{\partial V}{\partial \tau}+\nabla \frac{v^{2}}{2}-V \times(\nabla \times V)=-\nabla_{i}, \\
& \frac{1}{a^{2}}\left[\frac{\partial i}{\partial \tau}+\left\langle\nabla_{i}\right\rangle \mathbf{V}\right]+\nabla \mathbf{V}=0,
\end{aligned}
$$

where $a=$ sound velocity in the working medium, $i$ - enthalpy.

Enthalpy, pressure, and density increment, are related as:

$$
\mathrm{d} i=\frac{\mathrm{d} P}{P}, \quad \mathrm{~d} P=a^{2} \mathrm{~d} \rho \text {. }
$$

On the basis of Cauahy-Helmholts thoorem velocity in a dertain point of workiris medium can be represented as a vector sum

$$
\mathbf{v}=\mathbf{c}+\mathbf{v}_{\mathbf{a}}=\mathbf{c}+\nabla \phi
$$


where:

C - velocity of translational and rotational motion of absolutely incompressible liquid (vortical mode),

$V_{\text {a }}$ - velocity of pure deformation (acoustic mode),

$\phi$ - acoustic poteritial.

The problem being solved is two-dimentional. Introduce polar coordinato fyetem $\langle\Theta, R\rangle$ with the center at pump axis. Passing on to dimentionless variables as a linear, time scale and characteristic velocity one takes the impeller radius, main period of blades following oach othor and impeller circumferential velocity on the outer diameter $u_{2}$, respectively.

Dimensionless value of enthalpy oscillations relative to its magnitude in undisturbed flow is

$$
h=\frac{i-i_{0}}{U_{2}^{2}}=\frac{1}{U_{2}^{2}}{ }_{P_{0}}^{P} \frac{\mathrm{dP}}{\rho} \approx \frac{P-P_{0}}{\rho_{0} U_{2}^{2}} .
$$

Flow function and vorticity of vortical mode are introduced by the relations

$$
c_{m}=\frac{1}{r} \frac{\partial \Psi}{\partial \Theta}, \quad c_{u}=-\frac{\partial \Psi}{\partial r}, \zeta=\frac{1}{r} \frac{\partial}{\partial r}\left(r c_{u}\right)-\frac{1}{r} \frac{\partial C_{m}}{\partial \Theta},
$$

where $r, C_{m}, C_{u}$ - dimensionless radius and dimensionless velocity components of the vortical motion in meridional and tangential directions.

For numerical algorithm developing it is convenient to introduce a new coordinate system $(\eta, \xi)$ according to the relations

$$
\theta=\gamma n, r=e^{\gamma \xi} \text {. }
$$

where $\gamma$ - a certain constant.

Let $\Lambda=U_{2} z_{1}, 2 \pi \alpha$ be dimensionless similariti criterion of the given problem where $a_{1}$ - number of rotor blades, then acousto-vortical equations are written as

$$
\begin{gathered}
\Lambda^{2} \frac{\partial^{2} h}{\partial t^{2}}-\frac{1}{E^{2}}\left(\frac{\partial^{2} h}{\partial \eta^{2}}+\frac{\partial^{2} h}{\partial \xi^{2}}\right)=s, \\
\frac{\partial^{2} \Psi}{\partial \eta^{2}}+\frac{\partial^{2} \Psi}{\partial \xi^{2}}=-E^{2} \zeta, \\
\frac{\partial \zeta}{\partial t}=\frac{2 \pi}{\partial_{1} E^{2}}\left[\frac{\partial}{\partial \eta}\left(\frac{\partial \Psi}{\partial \xi} \zeta\right]-\frac{\partial}{\partial \xi}\left(\frac{\partial \Psi}{\partial \eta} \zeta\right)\right],
\end{gathered}
$$

where:

$$
\begin{gathered}
E=\gamma e^{\gamma \xi}, \quad s=S-\int_{0}^{1} S d t, \\
s=\frac{2}{E^{4}}\left[\left(\gamma \frac{\partial \Psi}{\partial \eta}-\frac{\partial^{2} \Psi}{\partial \xi \partial \eta}\right)^{2}-\frac{\partial \Psi}{\partial \xi^{2}}\left[r \frac{\partial \Psi}{\partial \xi}+\frac{\partial^{2} \Psi}{\partial \eta^{2}}\right]\right]
\end{gathered}
$$

Thus, the problem of determining pressure oscillations can be subdivided into two. The first one is that of incompessible liquid 
flow analysis for determination of the disturbins function $s$ and the second is the solution of nonuniform wavo oquation nolativo to enthalpy oscillations.

The flow model at the pump volute casing entry involving main flow features has been developed on the basis of experimental data results: The impeller exit flow is subdivided into an active zone and a wake zone. On the blade pressure side meridional velocity and flow angle are maximum and in the wake zone their values are minimum and constiant. In the active zone a meridional velocity component varies according to the linear law. Active flow zone size at the impeller exit depends on centrifugal impeller goometry, pump operation mode and leakaje value.

The volute casing walls are assumed absolutely rigid. In solving vortical equations the condition of wall flow "slipping" $\Psi$ = const, $\zeta_{w}=0$ is accepted, at an entry boundary

$$
\Psi(n, 0)=\gamma \int_{0}^{\gamma \eta} c_{2 m} d \eta \quad, \quad \zeta(n, 0)=-\frac{1}{\gamma} \frac{\partial C_{2 m}}{\partial \eta}
$$

at an exit boudary aw $a n=0$, $a \zeta / a n=0$. For an acoustic mode entry and exit specific acoustic impedances $Z_{i}$ and $Z_{G}$ are used.

Preliminary calculation showed that the affect of the exit boundary condition for vortical mode is not extended over than 2 grid nodes ahead up the stream. Besides vortex oscillations practically attenuate at the distance of one or one and a half blade cascade spacing from the entry cross-section which enables not to take into consideration vortical mode oscillations in giving a boundary condition at exit for enthalpy oscillation component as:

$$
\frac{\partial h}{E \partial \eta}=-\frac{\Lambda}{2} \frac{\partial h}{\partial t}
$$

At the entry boudary it is necessary to take into consideration available oscillations of both acoustic and vortical modes:

where:

$$
\frac{\partial h}{E \partial \xi}=-\frac{\Lambda}{Z_{i}} \frac{\partial h}{\partial t}-f
$$

$$
f=F-1 / r d t \quad, \quad F=\frac{z_{1}}{2 \pi \gamma} \frac{\partial C_{m}}{\partial t}-\gamma\left(C_{m}^{2}+C_{u}^{2}\right)+c_{u} \frac{\partial C_{m}}{\partial \eta} .
$$

For numerical solution of the acousto-vortical equations nonstationary finite-difference methods are used. Design region is covered by a uniform rectangular grid $(i, j)$ with steps $\Delta \eta, \Delta \xi$. Time srades (k), (l) with a step $\Delta t$, for vortical mode equations and with a step $\Delta t$ for a wave equation are used. Introduction of various time srades provides substantial economy in machine time and computer memory, for from the stability conditions $\Delta t_{a}<\Delta t$ approximately by 2 orders. In solving the wave equation with the step $\Delta t_{a}<\Delta t_{v}$ the values of disturbing function $s$ in the intermediate intervals of time are determined with the aid of interpolation by "slipping" polynoms in the fourth power as in Lagrange's formula.

Finite-difference analogues of differential equations in the inner sxid nodes are expressed by the formulae: 


$$
\begin{aligned}
& h_{i j}^{l+1}=2 h_{i j}^{l}-h_{i j}^{L-1}+\frac{\Delta t_{a}^{2}}{\Lambda^{2} E_{j}^{2}} \int \frac{h_{i j+1}^{l}-2 h_{i j}^{2}+h_{i j-1}^{2}}{\Delta \xi^{2}}+ \\
& \left.+\frac{h_{i+1 j}^{l}-2 h_{i j}^{l}+n_{i-1 j}^{l}}{\Delta n^{2}}\right]+\frac{\Delta t_{a}^{2}}{\Lambda^{2}} s_{i j}^{l}, \\
& \Psi_{i j+1}^{k}=-\left(\Delta \xi E_{j}\right)^{2} \zeta_{i j}^{k}+2\left[1+\frac{\Delta \xi^{2}}{\Delta \eta^{2}}\right] \Psi_{i j}^{k}-\frac{\Delta \xi^{2}}{\Delta \eta^{2}}\left[\Psi_{i+1 j}^{k}-\Psi_{i-1 j}^{k}\right]-\Psi_{i j}^{k} \text {, } \\
& \zeta_{i j}^{k+1}=\zeta_{i j}^{k}-\frac{\pi \Delta t_{v}}{2 \varepsilon_{1} E_{j}^{2} \Delta \gamma \Delta \xi}\left[C_{1} \times\left\{\begin{array}{l}
\zeta_{i j}^{k}\left(i f c_{1}>0\right\rangle \\
\left.\zeta_{i+1 j}^{k} \text { if } c \leq 0\right\rangle
\end{array}-C_{2} \times\left\{\begin{array}{l}
\zeta_{i-1 j}^{k}\left\langle i f c_{2}>0\right\rangle \\
\zeta_{i j}^{k}\left\langle i f c_{2} \leq 0\right\rangle
\end{array}+\right.\right.\right. \\
& +C_{3} \times\left\{\begin{array}{l}
\zeta_{i j}^{k}\left(\text { if } c_{3}>0\right) \\
\zeta_{i j+1}^{k}\left(\text { if } c_{3} \leq 0\right)
\end{array}-C_{4} \times\left\{\begin{array}{l}
\zeta_{i j-1}^{k}\left(\text { if } c_{4}>0\right) \\
\zeta_{i j}^{k}\left(i f c_{4} \leq 0\right)
\end{array}\right],\right.
\end{aligned}
$$

where: $C_{1}=\Psi_{i+1 j-1}^{k}-\Psi_{i+1 j+1}^{k}+\Psi_{i j-1}^{k}-\Psi_{i j+1}^{k}$,

$$
\begin{aligned}
& C_{2}=\Psi_{i, j-1}^{k}-\Psi_{i j+1}^{k}+\Psi_{i-1 j-1}^{k}-\Psi_{i-1 j+1}^{k}, \\
& C_{3}=\Psi_{i+1 j+1}^{k}-\Psi_{i-1 j+1}^{k}+\Psi_{i+1 j}^{k}-\Psi_{i-1 j}^{k}, \\
& C_{4}=\Psi_{i+1 j}^{k}-\Psi_{i-1 j}^{k}+\Psi_{i+1 j-1}^{k}-\Psi_{i-1 j-1}^{k}
\end{aligned}
$$

Numerical algorithm is realised in FORTRAN programs. One of them is written for the solution of the incompessible liquid motion equations in the $(\Psi, \zeta)$ form with the following calculation of the disturbing runction $s$. In another program the wave equation relative to enthalpy fluctuation is solved making use of function $s$ obtained. For the analysis of the calculation results auxiliary software has been created. Fig. 1 shows some results of the harmonic analysis for $h$ time runctions in selected grid nodes. It can be seen that computed and measured amplitudes are in agreement.

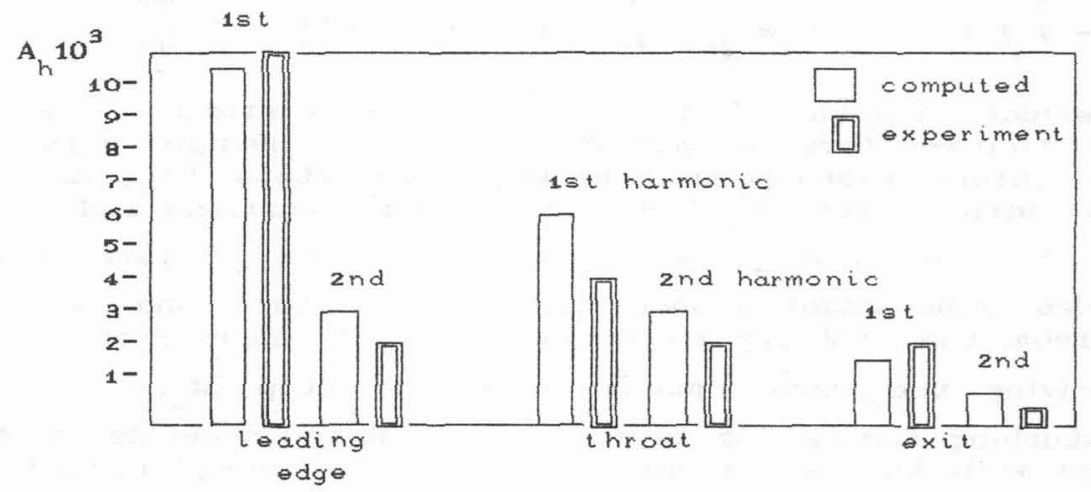

Fig. 1. - Distribution of pressure flactuation amlitudes along the volute casing length. 